\title{
Penerapan Nilai Kekeluargaan: Adakah lanya Penting?
}

\author{
Rahimah Jamaluddina ${ }^{*}$, Ab. Rahim Bakara, Siti Sa'adah Sulaiman ${ }^{b}$ \\ Jabatan Pendidikan Sains dan Teknikal, Fakulti Pengajian Pendidikan, Universiti Putra Malaysia, 43400 Serdang, Malaysia \\ ${ }^{b}$ Sekolah Menengah Kebangsaan Taman Seraya, 68100 Ampang, Malaysia \\ *Corresponding author: imah_upm@upm.edu.my
}

\begin{abstract}
This qualitative study aims to explore family values that inculcated by teachers in teaching family education and to examine the importance of teaching family education to the secondary school students. The respondents consisted of three secondary school teachers who teach three subjects which consist of family theme. Qualitative case study using semi-structured interviews, observation and video recording were conducted to collect the data. Interview transcriptions were analyzed using ATLAS.ti software to build themes in this study. The findings of this study clearly indicated that implementation of family values can increase student awareness towards positive values that should be practiced in family life. The findings also shows that inculcation of family values significantly associated with environmental aspects which give positive implications to the student not only can strengthen their family relationships but can improve students personality. Inculcation of family values should be given attention and priority by all parties, especially teachers and parents in determine student outcomes in the future.
\end{abstract}

Keywords: Family values; family education; qualitative case study

Abstrak

Kajian kualitatif ini bertujuan untuk meneroka nilai kekeluargaan yang diterapkan oleh guru dalam pengajaran kekeluargaan dan meneliti kepentingan pengajaran kekeluargaan kepada murid sekolah menengah. Responden kajian terdiri daripada tiga orang guru sekolah menengah yang mengajar tiga mata pelajaran yang mencakup tema kekeluargaan. Kajian kes kualitatif menggunakan teknik temu bual separa berstruktur, pemerhatian dan rakaman video dijalankan bagi mengumpul data. Transkripsi temubual dianalisis menggunakan perisian Atlas.ti bagi membina tema dalam kajian ini. Hasil kajian ini jelas menunjukkan bahawa penerapan nilai kekeluargaan dapat meningkatkan kesedaran murid tentang nilai positif yang patut diamalkan dalam kehidupan berkeluarga. Dapatan kajian juga menunjukkan bahawa penerapan nilai keluarga dengan ketara yang berkaitan dengan aspek alam sekitar yang memberikan implikasi positif kepada pelajar bukan sahaja dapat mengeratkan hubungan keluarga mereka tetapi boleh meningkatkan personaliti pelajar. Kepentingan penerapan nilai kekeluargaan perlu diberi perhatian dan keutamaan oleh semua pihak khususnya guru dan ibu bapa dalam menentukan kemenjadian murid pada masa hadapan.

Kata kunci: Nilai kekeluargaan; pendidikan kekeluargaan; kajian kes kualitatif

(C) 2017 Penerbit UTM Press. All rights reserved

\subsection{PENGENALAN}

Kebelakangan ini masyarakat Malaysia umumnya sering dikhabarkan dengan berita dan masalah yang berkait dengan keruntuhan akhlak dalam kalangan remaja serta permasalahan yang wujud dalam institusi keluarga. Masalah pergaulan bebas, pembuangan bayi, penderaan anak, pengabaian tanggungjawab anak terhadap ibu bapa serta jenayah yang mengakibatkan pembunuhan ahli keluarga sangat membimbangkan. Masalah ini tidak boleh dipandang remeh dan perlu ditangani segera kerana terbentuknya tamadun manusia di masa akan datang bergantung sepenuhnya pada generasi yang ada sekarang (Haryati, Sharifah Meryam \& Zakila, 2009). Pembinaan sebuah negara yang maju dan mampan memerlukan perancangan yang teliti. Tidak dinafikan, golongan Generasi Y atau generasi millennia (yang lahir antara 1981-1994) dan Generasi Z atau i Generation (yang lahir antara 1995-2010) merupakan golongan yang mewakili anak-anak pada usia remaja. Golongan ini sangat bergantung kepada teknologi dalam kehidupan mereka dan tidak memberi fokus kepada aspek dan nilai kekeluargaan (Siti Mahani \& Nazlinda, 2015) Kebergantungan mereka kepada teknologi lebih daripada kebergantungan terhadap nilai tuntutan asas manusia seperti berkomunikasi secara bersemuka merupakan antara halangan kepada mewujudkan masyarakat penyayang di negara ini. Oleh yang demikian, kejayaan sesebuah negara bukan diukur dari aspek kemajuan teknologi dan ekonomi semata-mata, malah aspek pembangunan sosial murid yang melibatkan nilai, emosi, rohani juga perlu diberi keutamaan.

\section{Latar Belakang Kajian}

Menyedari hakikat bahawa pentingnya peranan institusi keluarga dalam membentuk perpaduan dan keharmonian dalam kalangan masyarakat Malaysia. Maka Kementerian Pendidikan Malaysia telah membuat perancangan dalam Pelan Pembangunan Pendidikan Malaysia (PPPM 2013-2015) untuk menyediakan program pendidikan kekeluargaan supaya peranan ibu bapa dan komuniti dapat 
ditingkatkan. Aspirasi ini merupakan mekanisma yang diambil oleh pihak kerajaan bagi mencapai salah satu daripada cabaran Wawasan 2020 iaitu membentuk sebuah masyarakat yang berbudaya penyayang, sebuah sistem sosial yang lebih mementingkan masyarakat daripada diri sendiri dengan kebajikan rakyat tidak diasaskan kepada negara mahupun individu tetapi pada sistem kekeluargaan yang kukuh lagi mantap (Mahathir Mohamad, 1991).

Dalam konteks pendidikan di Malaysia, komponen kekeluargaan diajar secara merentas kurikulum bagi membolehkan murid mendapat pendedahan yang sewajarnya tentang kekeluargaan. Mata pelajaran yang mencakup komponen kekeluargaan adalah daripada mata pelajaran Ekonomi Rumah Tangga (ERT), Pendidikan Moral (PM), Pendidikan Jasmani Kesihatan (PJK), Pendidikan Sivik dan Kewarganegaraan (PSK) dan Pendidikan Islam (PI) (Huraian sukatan pelajaran KBSM ERT tingkatan 4 \& 5, Bahagian Kurikulum Teknikal \& Vokasional, 2003; Huraian sukatan pelajaran KBSM Pendidikan Moral, PPK 2003; Huraian sukatan pelajaran KBSM Pendidikan Jasmani dan Kesihatan, PPK 1999; Huraian sukatan pelajaran KBSM Pendidikan Sivik \& Kewarganegaraan, PPK 2004 dan Huraian sukatan pelajaran KBSM Islam, PPK 2003). Melalui pendekatan merentas kurikulum ini adalah diharapkan setiap murid akan mendapat pendedahan tentang kekeluargaan sekurang-kurangnya satu daripada lima mata pelajaran yang disediakan.

Jadual 1 Analisa peruntukan waktu pengajaran kekeluargaan per murid setahun bagi lima mata pelajaran

\begin{tabular}{|c|c|c|c|c|c|c|}
\hline Mata Pelajaran & $\begin{array}{c}\text { Peruntukan waktu } \\
\text { jam kontak bagi } \\
\text { kekeluargaan } \\
\text { setahun }\end{array}$ & $\begin{array}{c}\text { Peratus Jam kontak bagi } \\
\text { kekeluargaan setahun }\end{array}$ & $\begin{array}{c}\text { Murid } \\
\text { Islam }\end{array}$ & $\begin{array}{l}\text { Murid Islam yang } \\
\text { mengambil elektif } \\
\text { ERT }\end{array}$ & $\begin{array}{c}\text { Murid } \\
\text { Bukan } \\
\text { Islam }\end{array}$ & $\begin{array}{c}\text { Murid bukan } \\
\text { Islam yang } \\
\text { mengambil } \\
\text { elektif ERT }\end{array}$ \\
\hline Pendidikan Islam & $8 / 140$ & $5.71 \%$ & $5.71 \%$ & $5.71 \%$ & - & - \\
\hline Jasmani dan Kesihatan & $2 / 70$ & $2.85 \%$ & $2.85 \%$ & $2.85 \%$ & $2.85 \%$ & $2.85 \%$ \\
\hline Sivik dan & $6 / 70$ & $8.57 \%$ & $8.57 \%$ & $8.57 \%$ & $8.57 \%$ & $8.57 \%$ \\
\hline \multicolumn{7}{|l|}{ Kewarganegaraan } \\
\hline Pendidikan Moral & $14 / 140$ & $10 \%$ & - & - & $10 \%$ & $10 \%$ \\
\hline Ekonomi Rumah Tangga & $10 / 140$ & $7.14 \%$ & - & $7.14 \%$ & - & $7.14 \%$ \\
\hline Jumlah keseluruhan seora & d mempela & tan de & $17.13 \%$ & $24.27 \%$ & $21.42 \%$ & $28.56 \%$ \\
\hline
\end{tabular}

Jadual 1 menunjukkan analisis yang dijalankan oleh Rahimah (2012) ke atas huraian sukatan pelajaran KBSM bagi lima mata pelajaran, didapati seorang murid akan mempelajari tiga atau empat mata pelajaran yang mencakup aspek kekeluargaan dalam setahun. Dalam erti kata lain, bagi murid yang beragama Islam mereka akan mempelajari aspek kekeluargaan antara $17.1 \%$ hingga $24.3 \%$ setahun. Manakala bagi murid bukan beragama Islam pula, mereka mendapat pendedahan tentang kekeluargaan antara $21.4 \%$ hingga $28.6 \%$ setahun. Peratusan aspek kekeluargaan yang kecil ini menyebabkan wujudnya persepsi yang negatif pada segelintir masyarakat yang menganggap penerapan nilai kekeluargaan adalah tidak penting.

Hasil analisis ini juga menunjukkan bahawa kerajaan amat prihatin dan peka terhadap aspek penerapan nilai murni dan nilai kekeluargaan dalam kalangan murid sekolah. Lebih-lebih lagi dalam era perkembangan teknologi kini, wujud keperluan untuk menyediakan murid dengan ilmu kekeluargaan bagi membolehkan murid bersedia untuk memasuki alam dewasa, perkahwinan, keibubapaan dan membina sebuah institusi kekeluargaan yang harmonis. Oleh yang demikian institusi pendidikan, khususnya guru memainkan peranan yang sangat penting dalam mengembangkan nilai yang diingini untuk menjadikan murid warganegara yang bertanggungjawab, beretika dan bermoral. Justeru itu, kertas kerja ini akan mengkaji nilai kekeluargaan yang diterapkan oleh guru kepada murid serta meneliti kefahaman guru terhadap kepentingan penerapan nilai kekeluargaan.

\section{Objektif Dan Persoalan Kajian}

Tujuan kajian ini dijalankan adalah bagi meneroka nilai kekeluargaan yang diterap serta kepentingan penerapan nilai kekeluargaan dalam kurikulum sekolah menengah. Kajian ini diharapkan dapat menjawab persoalan kajian seperti berikut:

i. Apakah nilai kekeluargaan yang diterapkan oleh guru dalam pengajaran dan pembelajaran kekeluargaan?

ii. Apakah kepentingan penerapan nilai kekeluargaan kepada murid sekolah menengah?

\subsection{SOROTAN LITERATUR}

Keluarga merupakan unit sosial yang utama dan pertama bagi seorang anak, sebelum ia berkenalan dengan dunia sekitarnya. Fungsi utama keluarga adalah untuk membentuk, mengatur dan menyusun kehidupan anak supaya menjadi individu yang memiliki identiti sosial. Peranan keluarga juga penting dalam menjadikan anak seorang anggota masyarakat yang boleh bertingkah laku berdasarkan nilai asas dan jangkaan sosial masyarakat sekelilingnya (Abd. Rahim, Sufean \& Jamaludin, 2006). Pengalaman pergaulan dalam keluarga akan memberikan pengaruh yang sangat besar bagi perkembangan anak untuk masa yang akan datang. Keluarga akan memberikan warna kehidupan seorang anak, baik perilaku, budi pekerti mahupun adat kebiasaan sehari-hari.

Nilai didefinisikan sebagai perlakuan yang baik, peradaban dan tatasusila individu manusia dalam hubungannya sesama manusia, alam dan tuhan (Wan Mohd. Zahid, 1988). Nilai juga merujuk kepada garis panduan umum terhadap tingkah laku manusia (Raths, Harmin \& Simon, 1980). Nilai boleh diumpamakan seperti sel yang mencorakkan keperibadian dan jati diri seorang individu sama ada menjadi seorang yang berjaya ataupun sebaliknya. Penerapan nilai kekeluargaan telah banyak dibincangkan dalam kajian-kajian lepas. Antaranya mengikut perspektif Islam, nilai dikenali sebagai akhlak seperti kerajinan, keberanian, hormat menghormati, berdikari dan berhemah tinggi (Ali \& Erni Eryanti, 2005). Manakala Salhah, Amla, Zuria \& Saedah (2010), turut menyenaraikan nilai takwa, keikhlasan, hormatmenghormati, kasih sayang dan bersyukur dalam kajian mereka tentang remaja muslim. Abd. Rahim, Sufean \& Jamaludin (2006) dalam penulisannya menyatakan bahawa perubahan nilai dalam keluarga boleh mengakibatkan berlakunya pelbagai permasalahan sosial dalam masyarakat. Permasalahan sosial ini berlaku berpunca daripada institusi keluarga itu sendiri yang mana telah kehilangan fungsi sosialisasi 
dalam membina jati diri anak-anak. Jika dilihat pada keluarga kini, peranan ibu bapa sebagai model ikutan kepada anak-anak tidak lagi terserlah disebabkan oleh kesibukan ibu bapa dalam mencari rezeki serta pengaruh teknologi yang kian mencabar. Oleh yang demikian, tanggungjawab dalam menerapkan nilai kekeluargaan telah berpindah kepada guru yang dilihat signifikan dalam menyampaikan ilmu kepada murid.

Pendidikan kekeluargaan merupakan satu-satunya cabang ilmu yang memberi pendedahan secara langsung kepada murid tentang sistem keluarga (Rahimah, 2012). Pendidikan kekeluargaan memberi penekanan kepada domain afektif iaitu tumpuan kepada unsur-unsur kesedaran, sensitiviti, sikap, pertimbangan, emosi, pendirian dan sebagainya bertujuan untuk mengembangkan pemikiran moral dan aspekaspek kemanusiaan pada diri murid (Bloom, 1984). Secara umumnya pendidikan kekeluargaan diperkenalkan adalah bertujuan untuk menyediakan individu dengan kemahiran dan pengetahuan kekeluargaan supaya mereka boleh menangani masalah bagi menghadapi perubahan sosial yang wujud dalam masyarakat. Selain itu, pendidikan kekeluargaan mendidik generasi muda agar membuat perkaraperkara yang betul dan dapat mencegah remaja daripada terjebak dengan aktiviti gejala sosial yang tidak bermoral. Di samping itu, menerusi pendidikan kekeluargaan, guru membina nilai positif dalam diri murid bagi mengukuhkan jati diri murid agar mereka dapat menjana keupayaan diri untuk membangunkan sebuah institusi keluarga yang sihat, kuat dan berkualiti pada masa hadapan (Arcus, Schvaneveldt \& Moss, 1993; Saedah, Salhah \& Sharifah Mariam, 2014; Kenan \& Aysel, 2012).

Merujuk kepada Teori Perkembangan Moral Kohlberg (1988), dinyatakan bahawa pengajaran nilai merupakan tanggungjawab yang dapat membantu murid melalui beberapa peringkat perkembangan pemikiran moral. Kohlberg juga menegaskan bahawa pendidikan nilai berkait rapat dengan perkembangan personaliti pelajar. Bahkan menurut Agnieszka (2015), penerapan nilai kekeluargaan penting dalam membentuk sahsiah murid supaya mereka boleh berfikiran rasional dalam memenuhi tuntutan terhadap keperluan asas kehidupan. Di samping itu, nilai kekeluargaan yang diterapkan diharapkan membimbing mereka agar mencapai satu peringkat pemikiran dan kesedaran yang tinggi. Dalam konteks pengajaran kekeluargaan, kepentingan menyeluruh dapat dilihat apabila penerapan nilai yang dilaksanakan dapat memberi kesan positif bukan sahaja kepada diri murid dan keluarga malahan kepada sekolah dan masyarakat (Nurahimah \& Rafisah, 2010; Natas'a \& Theo, 2010).

\subsection{METODOLOGI KAJIAN}

Kajian ini menggunakan kaedah kualitatif dengan reka bentuk kajian kes iaitu satu kes berbilang tempat bagi meneliti proses pengajaran dan pembelajaran yang dijalankan oleh guru sekolah menengah dalam mengajar tema kekeluargaan. Kaedah kualitatif dipilih kerana penerapan nilai kekeluargaan merupakan satu proses yang kompleks yang memerlukan penerangan yang jelas dan menyeluruh (Creswell, 2005). Sampel kajian dipilih menggunakan teknik persampelan bertujuan. Sampel yang dipilih terdiri daripada tiga orang guru yang berpengalaman dalam mengajar tema kekeluargaan di sekolah menengah. Bagi membolehkan pengkaji memperoleh data yang mendalam dan terperinci, beberapa kriteria telah ditetapkan dalam membuat pemilihan sampel kajian. Dalam kajian ini, sampel kajian ditemubual secara mendalam dengan menggunakan soalan temubual separa struktur bagi menjawab persoalan kajian. Informan berada di lokasi yang berlainan tetapi mempunyai ciri-ciri dan sifat yang sama.

\subsection{DAPATAN KAJIAN}

\section{Nilai Kekeluargaan yang Diterapkan oleh Guru}

Dapatan yang diperolehi menunjukkan responden menerapkan pelbagai nilai kekeluargaan semasa melaksanakan pengajaran dan pembelajaran kekeluargaan samada secara langsung atau tidak langsung. Kesemua nilai yang diajar dilihat dapat membentuk sikap yang positif dalam diri murid.

\section{Nilai Kekeluargaan Yang Paling Banyak Diterapkan}

Berdasarkan temu bual dengan peserta kajian, dapatan kajian mendapati nilai yang paling banyak diterapkan oleh guru ialah hubungan dua hala antaranya nilai yang melibatkan hubungan murid dengan ahli keluarga atau dengan rakan-rakan. Keperluan menerapkan nilai ini ialah murid saling berkomunikasi dengan orang-orang di persekitarannya. Nilai yang dinyatakan ialah nilai bekerjasama, hormat-menghormati dan berkasih sayang.

Dapatan kajian menunjukkan nilai yang mengaitkan hubungan dengan ibu bapa dan keluarga merupakan nilai yang berulang-ulang kali diterapkan kerana keluarga merupakan institusi yang pertama bagi murid memulakan kehidupan. Temu bual berikut menunjukkan hubungan murid dengan keluarga yang dapat menjalinkan dan memupuk nilai kekeluargaan.

\footnotetext{
"Banyak nilai kekeluargaan yang akan diterapkan. Sebagai contoh nilai murni dia menghormati, kasih sayang, bekerjasama, bertoleransi, adil, saksama" (GPK, TM 2/104)

"Nilai murni yang dipaparkan adalah nilai murni kasih sayang, kerjasama antara ahli keluarga, menghormati keluarga" (GPSK, TM 1/190)

"Nilai yang nak diterapkan ialah kasih sayang, tanggungjawab yang perlu dimiliki oleh individu untuk membina keluarga dia sekarang dan keluarga yang akan datang" (GERT, TM 1/285)
}

Berdasarkan dapatan tersebut, jelaslah menunujukkan kajian yang dijalankan ke atas beberapa responden memberi jawapan bahawa nilai kekeluargaan sangat perlu diterapkan kerana dapat membentuk satu perhubungan yang positif antara murid dengan orang sekeliling terutama keluarganya. Lantaran itu, penerapan nilai yang diulang-ulang seperti nilai hormat-menghormati, berkasih sayang dan bekerjasama dapat membentuk murid yang bukan sahaja dapat berkomunikasi dengan berkesan, malah mempunyai kemahiran dalam pergaulan yang berkesan dengan orang lain. 


\section{Nilai Kekeluargaan Yang Mempunyai Hubungan Dengan Tuhan}

Dapatan daripada temu bual turut mendapati bahawa nilai kekeluargaan yang diterapkan dapat membina kekuatan jiwa dan membina keperibadian. Tidak dinafikan, penerapan nilai kekeluargaan melatih murid membina peribadi mulia melalui latihan mengamalkan sikap yang baik serta melihat contoh yang baik. Tidak ketinggalan, bimbingan guru melalui cerita-cerita teladan mahupun melalui proses pengajaran di dalam atau di luar bilik darjah memberi impak yang sangat mendalam yang banyak mempengaruhi perubahan positif murid. Matlamatnya tidak lain adalah bagi memupuk nilai yang baik yang sangat sesuai untuk membina jati diri setiap murid agar menjadi insan berakhlak mulia. Contohnya nilai tanggungjawab, bersyukur, amanah, menjaga maruah., berjimat, rasional, rajin dan prihatin.

Nilai Kekeluargaan Yang Dapat Membina Kekuatan Jiwa Ialah Nilai Tanggungjawab, Amanah, Menjaga Maruah Dan Bersyukur

Berdasarkan dapatan temu bual mendapati nilai yang dinyatakan ini sangat mempengaruhi pembinaan jiwa pelajar kerana nilai tersebut mempunyai kaitan secara langsung dengan hubungan pelajar dengan pencipta-Nya.

“Pelajar tersebut menjalankan tanggungjawab dan peranan yang sangat besar dalam keluarga ” (GPK, TM 2/120)

“Pelajar tersebut perlu menjaga maruah diri untuk menjaga nama baik keluarga" (GPSK, TM 1/199)

Nilai Kekeluargaan Yang Membina Keperibadian Seperti Nilai Rasional, Berjimat, Rajin, Berani Dan Prihatin

Berdasarkan dapatan daripada mendapati nilai-nilai ini jika berjaya diterapkan, sudah tentu akan dapat membina keperibadian yang mulia dalam diri pelajar.

“Kita ajar murid berfikir secara rasional. Contohnya, dia kena tahu akta tertentu semasa beli barang di kedai” (GERT, TM 1/249)

"Pelajar ini menjdi seorang yang bersikap rasional dalam menghadapi apa jua masalah dan situasi di dalam keluarga ” (GPK, TM 2/132)

"Kita terapkan dia macam mana menjadi pengguna yang bijak ni dengan strategi, teknik-teknik, macam mana membeli sesuatu barang, dia kena membuat perbandingan harga" (GERT, TM 1/229)

Hasil dapatan kajian daripada persoalan kajian pertama menunjukkan terdapat beberapa hubungan yang penting yang perlu diberi perhatian semasa penerapan nilai kekeluargaan iaitu nilai yang dapat memperkukuhkan hubungan pelajar dengan ahli keluarga serta pancipta-Nya. Tidak ketinggalan, kemampuan nilai yang diulang-ulang bagi membentuk kekuatan jiwa dan pembentukan keperibadian pelajar.

\section{Kepentingan Penerapan Nilai Kekeluargaan}

Menurut responden, nilai kekeluargaan sangat penting untuk diterapkan dalam diri murid kerana murid inilah nanti yang akan membentuk sebuah keluarga, menjadi anggota masyarakat dan seterusnya menyumbang kepada pembangunan sebuah negara. Berdasarkan temu bual dengan lima orang responden mendapati beberapa tema dapat dikenalpasti antaranya ;

\section{Mengeratkan Hubungan Kekeluargaan}

Dapatan kajian mendapati nilai bekerjasama, hormat-menghormati, tolong-menolong dan berkasih sayang merupakan nilai yang paling banyak diterapkan. Bukan sahaja guru-guru di sekolah, malahan ibu bapa di rumah juga berulang-ulang kali menekankan nilai ini. Hal ini memandangkan kehidupan murid di rumah memerlukan hubungan yang baik dengan ahli keluarga seperti ibu bapa, adik-beradik, datuknenek mahupun dengan pembantu rumah ataupun jiran tetangga. Lantaran itulah, nilai tersebut diterapkan hampir setiap masa di rumah terutama bagi pelajar yang mempunyai bilangan ahli keluarga yang ramai.

\footnotetext{
"Dia kena mengamalkan nilai-nilai kasih sayang kepada adik, ataupun sebagai adik kepada kakak ataupun abang dan juga tolong menolong di dalam ahli keluarga, yang mengukuhkan hubungan sesama ahli keluarga” (GPK, TM 2/128)

"Jadi apabila kita semaikan nilai murni ini dalam tema kekeluargaan ni, kita bakal melahirkan pelajar-pelajar yang menghormati keluarga dalam kalangan diri pelajar di samping mengeratkan hubungan kekeluargaan" (GPSK, TM 2/238)

"Apabila dia berkeluarga nantilah dan nilai-nilai kasih sayang ni sangat penting sebab bila keluarga tu teguh, hubungan bertambah erat. "(GERT, TM 1/091)
}

\section{Menerapkan Sikap Bertanggungjawab}

Berdasarkan dapatan, kebanyakan responden menekankan kepentingan nilai tanggungjawab kerana nilai ini dapat membentuk seorang pelajar yang memiliki sikap bertanggungjawab. Kesannya dapat melahirkan pelajar yang memahami peranan dan tanggungjawab yang sebenar-benarnya yang perlu diketahuinya sama ada sebagai anak, ahli keluarga ataupun ahli dalam masyarakat.

"Kalau dia sebagai kakak dia mesti bertanggungjawab, menjadi contoh dan tauladan yang baik kepada keluarga. Dia perlu mengambil tanggungjawab sebagai anak terhadap ibu bapanya yang tahu peranan sebagai anak"(GPK, TM 2/123) 
"Peranan yang perlu dimainkan oleh anak-anak merupakan tanggungjawab setiap ahli keluarga. Setelah dapat mengetahui peranan ibu bapa mereka terhadap mereka, sekaligus apabila mereka faham peranan ibu bapa mereka, mereka akan menghormati peranan tersebut dan tak timbul rasa tidak puas hati anak-anak terhadap ibu bapa mereka" (GPSK, TM 1/273)

"InsyaAllah kita berharap dia akan menjadi seorang yang bertanggungjawab. Keluarga yang akan dibina nanti adalah keluarga yang bahagia, keluarga yang damai yang tidak ada masalah keluarga porak peranda dan sebagainya"(GERT, TM 1/313)

Penerapan nilai kekeluargaan penting kerana dapat menanam sikap bertanggungjawab. Sikap bertartanggungjawab ini sangat penting dalam melahirkan pelajar yang memahami peranan, seterusnya menjalankan tanggungjawab yang digalas dalam keluarga dengan baik dan sempurna. Apabila nilai itu dapat diterap dengan baik, maka setiap ahli keluarga akan memainkan peranan yang sepatutnya bagi mengelakkan perselisihan dalam keluarga.

\section{Membina Jati Diri}

Dapatan daripada temu bual juga sangat bersetuju dengan kebaikan nilai kekeluargaan yang diterapkan oleh guru di sekolah dan diteruskan amalannya di rumah akan dapat membentuk jati diri dalam kalangan pelajar. Tidak dapat disangkal, setiap nilai kekeluargaan yang diterapkan seperti nilai tanggungjawab, bersyukur, amanah, menjaga maruah., berjimat, berdisiplin, rasional, rajin, prihatin dan semangat patriotisme merupakan nilai positif yang dapat membentuk keperibadian mulia dalam diri pelajar. Dapatan ini digambarkan seperti temu bual berikut ;

"Pelajar yang berdisiplin akan sama-sama ajak kawan tu berdisiplin, tepat masa, maksudnya ikut jadual, datang tepati masa. Maksudnya melahirkan rasa bertanggungjawab"(GERT, TM 1/924)

"Biasanya pelajar-pelajar yang mengamalkan nilai-nilai yang baik di sekolah melalui aktiviti kurikulum ataupun ko-kurikulum yang menonjolkan bakat mereka. Biasanya pelajar ini akan menjadi contoh yang baik, terbaik kepada guru dia, kepada rakan-rakan dan seterusnya menjadi ikon masyarakat"(GPK, TM 2/164)

Penerapan nilai kekeluargaan penting dalam membina jati diri murid agar mereka menjadi individu yang boleh berfikiran rasional, bersemangat waja dan mempunyai keberanian dalam menghadapi cabaran pada masa kini. Banyak nilai positif dapat dilihat melalui perwatakan dan jati diri yang ditonjolkan oleh pelajar. Jati diri seumpama inilah yang diharapkan wujud dalam setiap diri pelajar kerana sangat penting dalam mewujudkan sebuah keluarga, masyarakat dan negara yang harmoni dan sejahtera.

Akhirnya, tema yang dapat dicungkil daripada analisis temu bual menyokong secara positif untuk meneruskan amalan penerapan nilai kekeluargaan di sekolah dan perlu diteruskan di rumah. Hal ini memandangkan, nilai kekeluargaan bukan sekadar memberi kebaikan kepada persekitaran terdekat murid sahaja, malahan turut memberi kebaikan kepada sekolah, masyarakat dan negara.

\subsection{PERBINCANGAN}

Secara umumnya, dapatan kajian menunjukkan guru-guru yang mengajar tema kekeluargaan sangat komited dalam menerapkan nilai kekeluargaan kepada pelajar. Bahkan guru juga menyokong agar penerapan nilai keluarga diberi penekanan dan diamalkan dalam kehidupan seharian. Antara nilai kekeluargaan yang diterapkan oleh guru adalah nilai yang menunjukkan hubungan dua hala seperti nilai kasih-sayang, hormat-menghormati, bertolak ansur dan bekerjasama. Manakala nilai kekeluargaan yang menunjukkan hubungan dengan Tuhan sangat penting diterapkan agar menambah kekuatan jiwa pelajar. Antaranya nilai bertanggungjawab, menjaga maruah, berjimatcermat, menjaga maruah, rajin, prihatin dan semangat patriotisme.

Dapatan kajian ini disokong oleh Mohd Azhar, Azmi Shah, Mohamad Fauzi (2001) dalam kajian mereka tentang nilai asas seperti ketaqwaan, keikhlasan, hormat-menghormati, kasih sayang dapat diterapkan di dalam keluarga. Tema kajian ini menyokong kajian Zaharah Hussin (2005) tentang peranan guru Pendidikan Islam dalam mendidik generasi berakhlak mulia iaitu menekankan nilai murni yang mempunyai kaitan dengan hubungan dengan Allah dan hubungan dengan orang persekitaran.

Seterusnya, nilai asas dalam keluarga ini perlu diterapkan kepada murid sejak dari awal lagi supaya nilai ini menjadi budaya dan sebahagian daripada jati diri pelajar. Dapatan kajian ini disokong oleh kajian Abd Rahim, et al., (2006) iaitu kepentingan penerapan nilai dapat membina jati diri murid agar mereka dapat bertindak balas terhadap jangkaan sosial masyarakat sekeliling dengan lebih baik. Begitu juga dengan kajian sebelumnya oleh Agnieszka (2015) dan Salhah, Amla, Zuria \& Saedah (2010) yang menyatakan murid boleh membuat pertimbangan, berfikir secara rasional, tahu menjaga maruah diri dan dapat menjalankan amanah dan tanggungjawab yang diberi dengan sempurna selepas memiliki nilai positif dalam diri.

Responden juga bersetuju bahawa nilai kekeluargaan yang diajar boleh memberi manfaat iaitu kebaikan kepada murid pada masa akan datang. Seterusnya, memberi sumbangan yang besar kepada keluarga, sekolah, masyarakat dan negara. Dapatan kajian ini selari dengan dapatan beberapa kajian terdahulu yang menjelaskan bahawa penerapan nilai kekeluargaan penting kerana dapat mewujudkan keluarga yang penuh kasih sayang (Nur Zahidah \& Raihanah, 2011). Begitu juga kajian lain yang mempunyai dapatan tentang keperluan setiap ahli dalam keluarga tahu akan peranan dan tanggungjawab masing-masing (Ratna Roshida \& Nik Haslinda, 2007). Hal ini memandangkan penerapan nilai yang utuh ini juga akan dapat mengeratkan hubungan kekeluargaan serta mewujudkan suasana kebahagiaan dalam keluarga (Ratna Roshida \& Nik Haslinda, 2007).

Seterusnya, responden kajian juga sependapat menyatakan bahawa nilai kekeluargaan penting dalam melahirkan pelajar yang bertanggungjawab. Individu yang bertanggungjawab ini dapat memberi sumbangan yang besar bukan sahaja kepada keluarga, malah kepada sekolah, masyarakat dan negara. Dapatan kajian lepas yang selari dengan dapatan kajian ini ialah murid-murid ini dapat mengharumkan nama sekolah dengan akhlak mulia dan menjadi kebanggaan guru-guru serta pihak sekolah (Widding, Göran, Berge, BrittMarie, 2014). Kemudian menjadi ikon dalam masyarakat (Natas’a \& Theo, 2010) 
Oleh yang demikian, adalah penting bagi seorang guru untuk memiliki pengetahuan, kesedaran dan penghayatan yang tinggi terhadap penerapan nilai kekeluargaan. Tugas guru di sekolah perlu diteruskan pula oleh ibu bapa ataupun ahli keluarga di rumah agar amalan penerapan nilai kekeluargaan berterusan dan tidak mudah dilupakan.

\subsection{KESIMPULAN}

Dapat disimpulkan bahawa penerapan nilai kekeluargaan adalah sangat penting untuk diterapkan kepada murid khususnya generasi Y dan $\mathrm{Z}$ yang ada pada masa sekarang. Nilai kekeluargaan perlu diterap dalam diri murid sejak dari bangku sekolah lagi bagi membina jati diri mereka agar lebih bersedia untuk menghadapi pelbagai cabaran dan kemelut sosial di masa akan datang. Dapatan yang diperolehi juga menunjukkan guru sedar akan kepentingan penerapan nilai kekeluargaan dalam diri murid. Bahkan guru bersedia untuk menggalas tanggungjawab sebagai agen sosialisasi kepada murid bagi memastikan murid membesar dalam acuan yang sempurna dan selari dengan kehendak persekitaran sosial.

Dapatan yang diperolehi juga menunjukkan bahawa langkah yang diambil oleh KPM dalam menerapkan nilai kekeluargaan secara merentas kurikulum adalah sangat wajar dan perlu diteruskan. Walaupun, komponen kekeluargaan mencatatkan peratusan yang kecil dalam sukatan pelajaran di peringkat sekolah menengah. Namun peratusan yang kecil ini mampu memberi sumbangan yang besar dalam usaha membangunkan modal insan kelas pertama yang beretika, bermoral serta memiliki jati diri yang kukuh bagi menangani kehendak globalisasi. Justeru itu, guru yang mengajar kekeluargaan perlu sentiasa melengkapkan diri dengan pelbagai ilmu yang berkaitan dengan pengajaran kekeluargaan. Ini akan dapat membantu guru dalam menghasilkan pengajaran yang berkualiti dan berkesan di masa akan datang.

Rujukan

Abd. Rahim, A., Sufean , H., \& Jamaludin, T. (2006). Institusi Keluarga: Menghadapi Cabaran Alaf Baru. Selangor: Utusan Publication \& Distribution. Agnieszka. (2015). What Do Children Learn From Their Parents And What From Their Grandparents. Procedia-Social and Behavioral Sciences, 174, $2467-2472$. Ali, Erni Eryanti. (2005). Penghayatan Nilai-Nilai Murni Ke Arah Pembentukan Disiplin Pelajar. Prosiding Seminar Pendidikan JPPG.

Arcus, M. E., Schvaneveldt, J. D., \& Moss, J. J. (1993). Handbook of Family Life Education: The Practice Of Family Life Education. Newburry Park: California: SAGE Publication, Inc.

Bloom, B. S. (1984). Taxonomy of Educational Objective Book 1: Cognitive Domain (2 ${ }^{\text {nd }}$ ed.). New York: Addison Wesley Publishing Company.

Creswell, J. W. (2005). Educational Research: Planning, Conducting, And Evaluating Quantitative And Qualitative Research (2 ${ }^{\text {nd }}$ ed.). Upper Saddle River, NJ: Merill.

Haryati Shafii, Sharifah Meryam Shareh Musa, \& Zakila Abd Rahman. (2009). Pembangunan Modal Insan Ke Arah Meningkatkan Kualiti Hidup Masyarakat. International Conference on Human Capital Development (ICONHCD) 25-27 May 2009, Kuantan Pahang.

Kementerian Pendidikan Malaysia. (2003). Huraian Sukatan Pelajaran Ekonomi Rumah Tangga. Selangor: Bahagian Kurikulum Teknikal dan Vokasional.

Kementerian Pendidikan Malaysia. (2012). Pelan Pembangunan Pendidikan Malaysia 2013-2015 (Pendidikan Pra Sekolah Hingga Lepas Menengah).

Kenan \& Aysel. (2012). Students' families and family values. Procedia - Social and Behavioral Sciences, 47, 501-506.

Mahathir Mohamad. (1991). Wawasan 2020. moe.gov.my.

Mahathir, M. (1991, Februari). Malaysia: The Way Forward. Kertas Kerja Yang Dibentangkan di Persidangan Majlis Perdagangan Malaysia di Kuala Lumpur.

Mohd. Azhar, A. H., Azmi Shah, S., \& Muhamad Fauzi, O. (2001). Senario Pendidikan Moral masyarakat Melayu zaman Teknologi Komunikasi Maklumat (ICT): Trend, hala tuju, dan Model Pendidikan Moral Keluarga Islam. Jurnal Teknologi, 35, 45-70.

Mohd. Azhar, A. H., Azmi Shah, S., \& Muhamad Fauzi, O. (2001). Senario Pendidikan Moral masyarakat Melayu zaman Teknologi Komunikasi Maklumat (ICT): Trend, hala tuju, dan Model Pendidikan Moral Keluarga Islam. Jurnal Teknologi, 35, 45-70.

Natas`a Pantic' \& Theo Wubbels. (2010). Teacher competencies as a basis for teacher education-Views of Serbian. Teaching and Teacher Education 26, 694-703.

Nur Zahidah Hj Jaapar \& Raihanah Hj Azahari. (2011). Model Keluarga Bahagia Menurut Islam, Jurnal Fiqh, 8, 25-44.

Nurahimah \& Rafisah. (2010) Hubungan Kualiti Penyeliaan Dan Pengajaran Di Bilik Darjah Dengan Efikasi Kendiri Guru. Asia Pacific Journal of Educators and Education, 25, 53-71.

Pusat Perkembangan Kurikulum. (1999). Huraian Sukatan Pelajaran KBSM Pendidikan Jasmani dan Kesihatan. Kuala Lumpur: Kementerian Pelajaran Malaysia.

Pusat Perkembangan Kurikulum. (2003). Huraian Sukatan Pelajaran KBSM Pendidikan Moral. Kuala Lumpur: Kementerian Pelajaran Malaysia.

Pusat Perkembangan Kurikulum. (2003). Huraian Sukatan Pelajaran KBSM Pendidikan Islam. Kuala Lumpur: Kementerian Pelajaran Malaysia.

Pusat Perkembangan Kurikulum. (2004). Huraian sukatan pelajaran KBSM Pendidikan Sivik dan Kewarganegaraan. Kuala Lumpur: Kementerian Pelajaran Malaysia.

Rahimah, J. (2012). Pengaruh Faktor Terpilih Terhadap Efikasi Kendiri Guru Sekolah Menengah Dalam Melaksanakan Pengajaran Kekeluargaan. Tesis Ijazah Doktor Falsafah yang tidak diterbitkan, Universiti Putra Malaysia.

Raths, L., Harmin, M., \& Simon, S. (1976). Selection From Values And Teaching: Dalam David, P. (ed.) Moral Outrage in Education. Peter Lang Publishing: New York.

Ratna Roshida \& Nik Haslinda. (2007). Peranan Institusi Keluarga Dalam Penjanaan Bangsa Bertamadun. Jurnal Kemanusiaan, 9, 73-82.

Saedah A. Ghani, Salhah Abdullah, Sharifah Mariam Syed Akil. (2014). Muslim Adolescents Moral Value And Coping Strategy Among Muslim Female Procedia Social and Behavioral Sciences, 114, 427-433. Elsevier Ltd.

Salhah, Amla, Zuria \& Saedah. (2010). Moral Value Inventory for Muslim Adolescents. International Conference on Learner Diversity. Elsevier Ltd.

Siti Mahani Mahazir \& Mazlinda Ismail. (n.d.). Generasi Z: Tenaga Kerja Dan Cabarannya. Retrieved from http://docs.jpa.gov.my/docs/ pelbagai/Artikel/2015/Generasi_Z.pdf

Wan Mohd. Zahid Mohd. Noordin. (1988) Ke Arah Pelaksanaan Nilai-Nilai Murni di dalam KBSM: Falsafah Pendidikan Negara. Kertas kerja yang dibentangkan dalam Seminar Nilai-nilai Murni Merentas Kurikulum Dalam KBSM di Universiti Kebangsaan Malaysia, Bangi, Malaysia.

Widding, Göran, Berge, Britt-Marie. (2014). Teachers`'And Parents`́ Experiences Of Using Parents As Resources in. Procedia-Social and Behavioral Sciences, 116, $1587-1593$.

Zaharah Hussin. (2005). Mendidik Generasi Berakhlak Mulia: Fokus Peranan Guru Pendidikan Islam. Masalah Pendidikan, (July), 79-95. The Territiry. California: Phil Delta Kappa. 